\title{
Characterizing Airborne Phthalate Concentrations and Dynamics in a Normally Occupied Residence
}

David M Lunderberg ${ }^{1,2}$, Kasper Kristensen ${ }^{2 \#}$, Yingjun Liu ${ }^{2 \dagger}$, Pawel K Misztal ${ }^{2 \dagger}$, Yilin Tian ${ }^{2,3}$, Caleb Arata ${ }^{1,2}$, Rebecca Wernis $^{2,3}$, Nathan Kreisberg ${ }^{4}$, William W Nazaroff ${ }^{3}$, and Allen H Goldstein ${ }^{2,3, *}$

${ }^{1}$ Department of Chemistry, University of California, Berkeley, CA, USA.

${ }^{2}$ Department of Environmental Science, Policy, and Management, University of California, Berkeley, CA, USA.

${ }^{3}$ Department of Civil and Environmental Engineering, University of California, Berkeley, CA, USA.

${ }^{4}$ Aerosol Dynamics Inc., Berkeley, CA, 94710, USA

\# Now at Department of Engineering, Aarhus University, Denmark

$\uparrow$ Now at BIC-ESAT and SKL-ESPC, College of Environmental Sciences and Engineering, Peking University, China

† Now at Centre for Ecology \& Hydrology, Edinburgh, Scotland, UK

*Corresponding email: david_lunderberg@berkeley.edu

14

15 SI Contains:

1614 pages

179 figures

18

19

20

21

22

23

24

25

26

27

28

29

30

31 


\section{SV-TAG Operation:}

In this study, the SV-TAG resided in an external temperature-controlled shed built specifically to contain instrumentation throughout the campaign. The SV-TAG unit was situated approximately $0.5 \mathrm{~m}$ from the residence. The SV-TAG instrument is equipped with two sampling cells that are operated in parallel. One sampling cell was dedicated to measuring indoor gas-plus-particle concentrations. It sampled through a 1.6-m stainless steel inlet extending from the house's dining room. The inlet was positioned approximately $30 \mathrm{~cm}$ from the exterior room wall and $1.5 \mathrm{~m}$ above the floor. A second cell alternately collected indoor air from the same indoor inlet or from a separate outdoor air sampling port through a $2.0-\mathrm{m}$ stainless steel tube extending outside the shed. The second cell was switched hourly among four states: indoor gas-plus-particle, indoor particle only, outdoor gas-plus-particle, and outdoor particle only, with a complete cycle occurring every four hours. Gas-phase removal for the particle-only measurements was accomplished by passing sample air through a carbon monolith denuder ( 500 channels, $30 \mathrm{~mm}$ OD $\times 40.6 \mathrm{~cm}$; MAST Carbon) thereby removing all gas-phase organic compounds from the air stream before collection. Particle-only measurements (and corresponding gas-particle partitioning measurements) determined by the denuder method have, if any, a negative bias due to repartitioning and loss within the denuder. ${ }^{1}$ Gas-particle partitioning of phthalates may be influenced by sorption of gas-phase species to sampling lines; however, past investigations indicate that such biases are minimal for the experimental conditions of this study. ${ }^{2,3}$ Concurrent gas-plus-particle measurements in the two cells were used to normalize any cell differences when quantifying gas-particle partitioning. This cell-correction factor was adjusted downwards in the case of DEHP such that gas-particle partitioning maximized at $100 \%$ in the particle phase.

Both cells sampled air at $10 \mathrm{~L} / \mathrm{min}$ through a PM2.5 cyclone (BGI, Inc.; SCC 2.654) for the first 15 minutes of each hour for the duration of the campaign. During sampling, the cell temperatures were controlled at $30{ }^{\circ} \mathrm{C}$. After sample collection, the captured organic mass was thermally desorbed by raising the collection cell temperature to $320^{\circ} \mathrm{C}$. The organic mass was carried by helium gas saturated with a derivatization agent, MSTFA (N-methyl-N-(trimethylsilyl)trifluoroacetamide, > 98.5\%, Sigma Aldrich), towards a concentrating trap before valveless injection into an Agilent 7890A gas chromatograph. Separation was achieved by linearly ramping the temperature $\left(50{ }^{\circ} \mathrm{C}\right.$ to $330{ }^{\circ} \mathrm{C}$, over 14 minutes) with helium flow ( 0.5 standard $\mathrm{cm}^{3} / \mathrm{min}$ to 1.0 standard $\mathrm{cm}^{3} / \mathrm{min}$ through minute 12 , then 1.0 standard $\mathrm{cm}^{3} / \mathrm{min}$ to $3.0 \mathrm{standard} \mathrm{cm}^{3} / \mathrm{min}$ to the end) through the column (Restek, Rtx-5Sil MS, $20 \mathrm{~m} \times 0.18 \mathrm{~mm} \times 0.18 \mu \mathrm{m}$ ). Species exited from the column into an Agilent 5975C quadrupole mass spectrometer (MS) for subsequent electron impact (EI) analysis. Mass spectral interpretation and quantification used a single-ion peak fitting approach via the TERN software. ${ }^{4}$

Time-resolved measurements of DEP, DIBP, DBP, and DEHP were acquired hourly. Peak areas were normalized by deuterated internal standards to account for cell-loading matrix effects and a general ion source decline over the duration of the field campaign. DBP, DIBP, and DEHP were normalized to dibutyl phthalate-3,4,5,6-d4 (Sigma Aldrich), a deuterated analogue of DBP. DEP was normalized to a deuterated isotopologue of 
pentadecanol, considering similarities in retention time. Absolute concentrations were determined by multipoint linear calibration curves with a zero-point intercept that were generated every four days during the campaign. Calibration standards from the EPA 525 update phthalate esters mix were added to a 50/50 methanol/chloroform solution with other relevant chemical standards. Limits of detection (LODs), set at $3 \times$ the background chromatographic signal, are analyte dependent and variable depending on acquisition parameters, instrument status, chromatographic coelutions, and matrix interferents. These same factors affect uncertainties, which are typically less than $20 \%$ on a relative scale. ${ }^{5}$ Typical LODs for DEP, DIBP, and DBP were on the order of $10 \mathrm{ng} / \mathrm{m}^{3}$. Typical LODs for DEHP were on the order of $1 \mathrm{ng} / \mathrm{m}^{3}$.

Throughout the campaign, three phthalate species (DEP, DBP, and DEHP) were identified by authentic external standards and a fourth (DIBP) was identified referencing mass spectra available in the NIST/EPA/NIH Mass Spectral Library.${ }^{6,7}$ Major phthalate species, excluding dimethyl phthalate, have a prominent characteristic ion at $m / z=149$. This characteristic ion was used to search for other phthalate species during periods with high temperature and high particle mass concentrations, when phthalate concentrations are expected to be highest. No additional species above background chromatographic signal were identified as phthalates; see Figure S1 of the Supporting Information.

\section{SV-TAG Quality Assurance and Quality Control:}

Method Blanks: Method blanks were conducted at the beginning, middle, and end of the sampling campaign by injecting pure solvent containing only deuterated internal standards onto the thermal desorption collection cells via an automated liquid injection system. Possible contamination of blanks by phthalates could occur from incomplete desorption of the collection cells, or from release of plastic components within the SVTAG system. Such artifacts were minimally observed. Measured phthalate signals during method blank measurements relative to the prior gas-plus-particle measurement were: DEP: $<0.5 \%$; DIBP: $<3 \%$; DBP: $<4 \%$; DEHP: $<5 \%$.

Internal Standards: The primary purpose of the internal standard was to account for any changes in the efficiency of the analytical system as a function of time during the experiment. A solvent solution containing 45 deuterated internal standards was injected onto the thermal desorption collection cell on top of each ambient air sample by an automated injection system. These internal standards encompassed a broad range of chemical functionalities and volatilities. All internal standards qualitatively showed similar trends, with decreased responses being observed as the campaign progressed owing to degraded performance of the mass spectrometer's ion-source as it become dirtier. Internal standard responses were restored after an ion-source cleaning. Some variability in response was also observed, presumably because of sample matrix effects; these were corrected based on the internal standard response.

External Standards: External standards were run every 25 hours such that a three-point calibration curve was generated every three to four days. After internal standard normalization to account for changes in the mass spectrometer's ion-source and sample matrix effects, calibration curves did not significantly differ over the course of the measurement period. 


\section{3}

Sensitivity Testing: Although particle densities are known to vary, such as during different types of source events, we assume a constant particle density of $1.67 \mathrm{~g} / \mathrm{cm}^{3}$ in congruence with past studies. ${ }^{8,9}$ Sensitivity testing was conducted by renormalizing particle mass concentrations using densities of 1 and $2 \mathrm{~g} / \mathrm{cm}^{3}$, approximately spanning the range of expected values. Using these extrema, the slope of Figure 3 could vary between 1.9 and $3.8 \mathrm{ng} / \mu \mathrm{g}$ (parts per thousand), the slope of Figure 4A could vary between 1.4 and $2.8 \mathrm{ng} / \mu \mathrm{g}$ (parts per thousand), and the resulting estimate of $K_{\mathrm{p}}{ }^{*}$ in Figure 5 could vary between 2.0 and $4.0 \mathrm{~m}^{3} / \mu \mathrm{g}$.

Data Selection: Non-representative house venting occurred between the occupied and vacant periods; four associated measurements were excluded from analysis. One singlepoint particle concentration determined from the Grimm 11-A particle counter on 21 Dec 2017 was similarly excluded. The point corresponded to the beginning of an emission event and may not have been fully representative of the house because of incomplete mixing. 


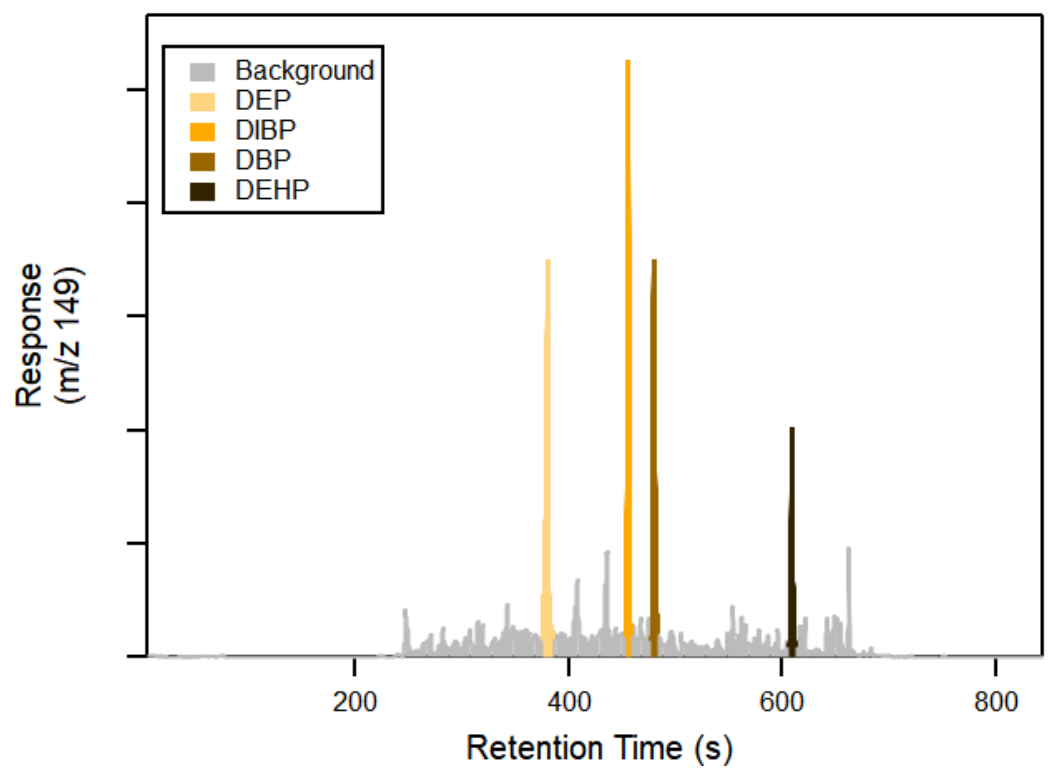

Retention Time (s)

143 Figure S1: The response of ion $\mathrm{m} / \mathrm{z}=149$ is plotted against the chromatograph retention time on 14416 Dec 2017, a period of high particle loading when phthalate levels are expected to be elevated. 145 Phthalate diesters (other than dimethyl phthalate) have a prominent characteristic ion at $\mathrm{m} / \mathrm{z}=$ 146 149. In the above spectrum, DEP, DIBP, DBP, and DEHP were clearly identified in comparison 147 to a mass spectral database and the known retention times of authentic external standards (EPA 148525 phthalate esters update mix: DMP, DEP, DBP, DEHP, butyl benzyl phthalate). No other 149 species above chromatographic background levels were identifiable as phthalates in reference to 150 the NIST/EPA/NIH Mass Spectral Library over the selected analysis periods. 

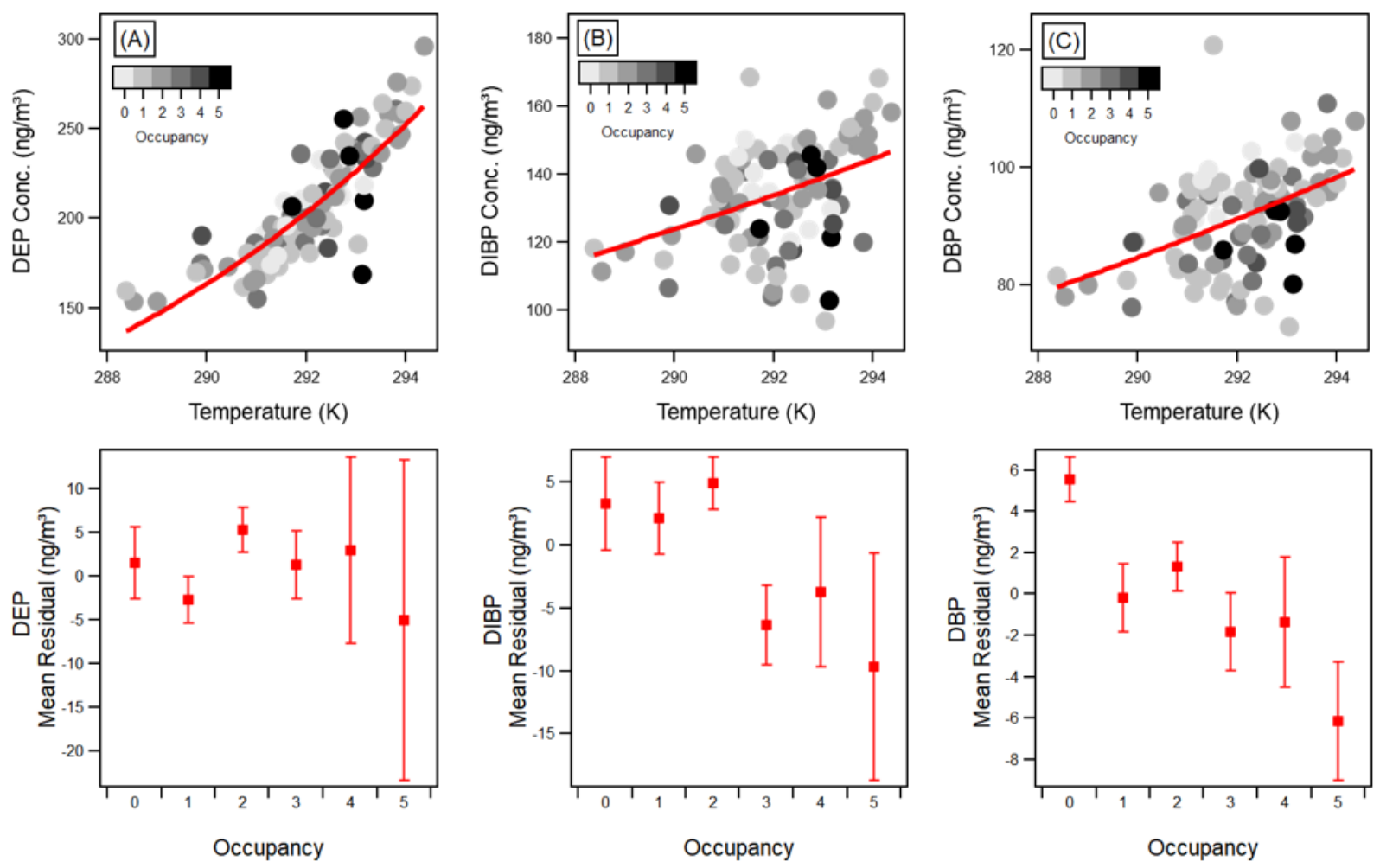

Figure S2: Upper: Total (gas-plus-particle) indoor phthalate concentrations are plotted against temperature during waking hours of the occupied period. Lower: The residuals of respective exponential fits are compared against residential occupancy, where uncertainties correspond to the standard error of the mean. Parameters of the exponential fits $\left(y=A e^{k x}\right)$ are: $A=3.5 \times 10^{-12}, k=0.109, R^{2}=0.73$ (panel A), $A=1.8 \times 10^{-3}, k=0.038, R^{2}=0.15$ (panel B), $A$ $157=1.6 \times 10^{-3}, k=0.038, R^{2}=0.23$ (panel $\mathrm{C}$ ). Units of measure on the fit parameters are inverse 158 temperature for $k(1 / \mathrm{K})$ and concentration for $A\left(\mathrm{ng} / \mathrm{m}^{3}\right)$. 

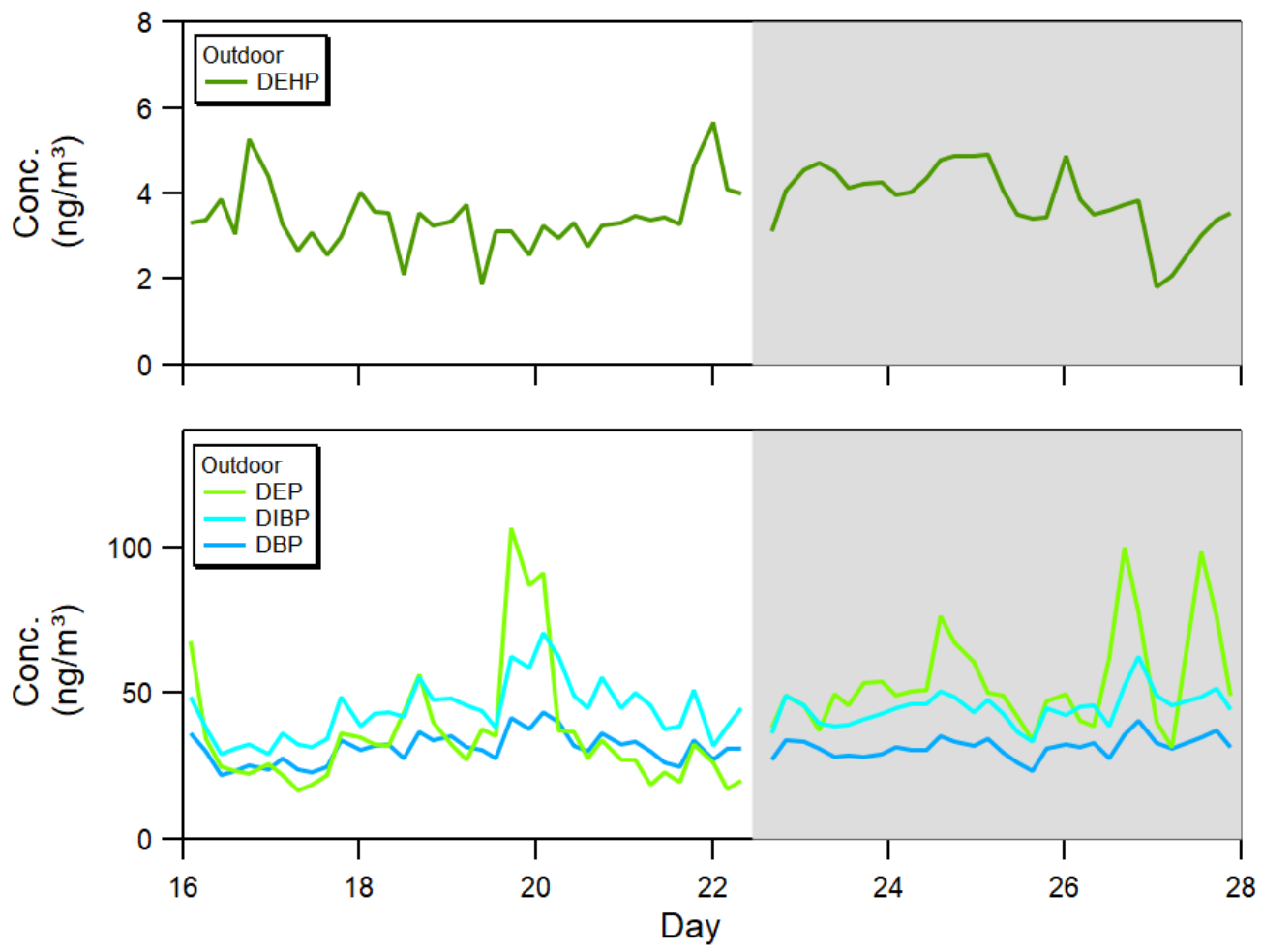

160

161

162

163

164

Figure S3: The gas-plus-particle outdoor concentrations of DEP, DIBP, DBP, and DEHP are displayed, where the shaded region corresponds to the vacant period. 


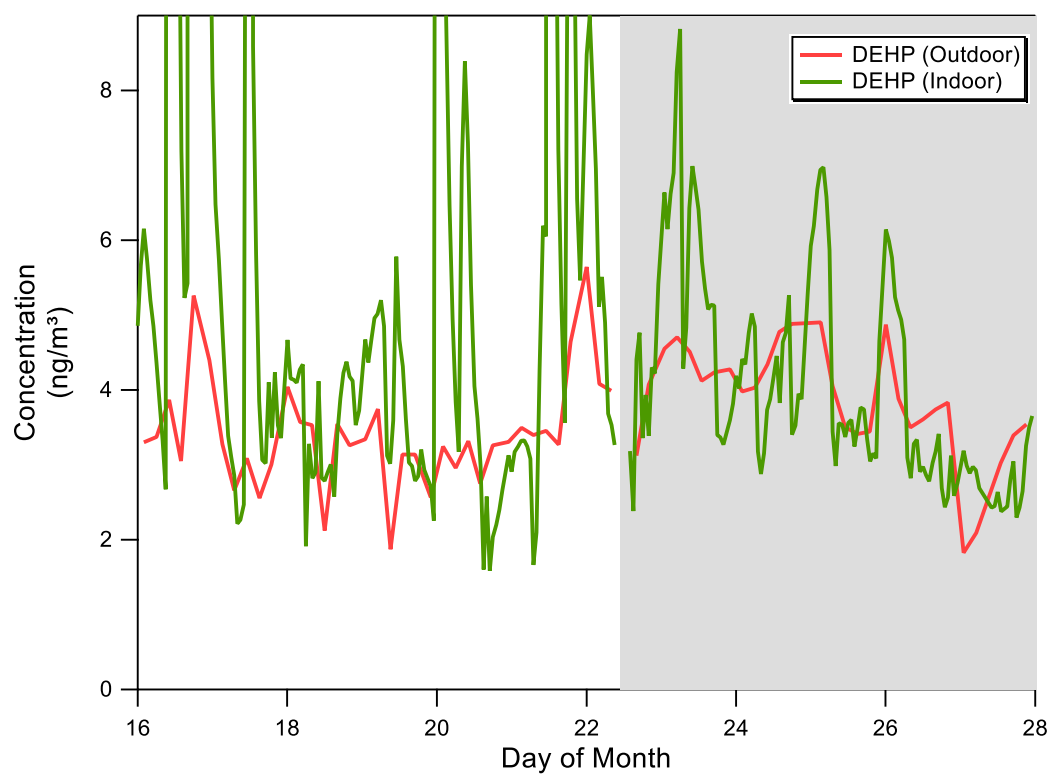

165

166 Figure S4: The total (gas-plus-particle) indoor and outdoor concentrations of DEHP are

167 displayed, where the scaling emphasizes baseline concentrations and excludes episodic 168 concentrations above $9 \mathrm{ng} / \mathrm{m}^{3}$. The shaded region corresponds to the vacant period. 

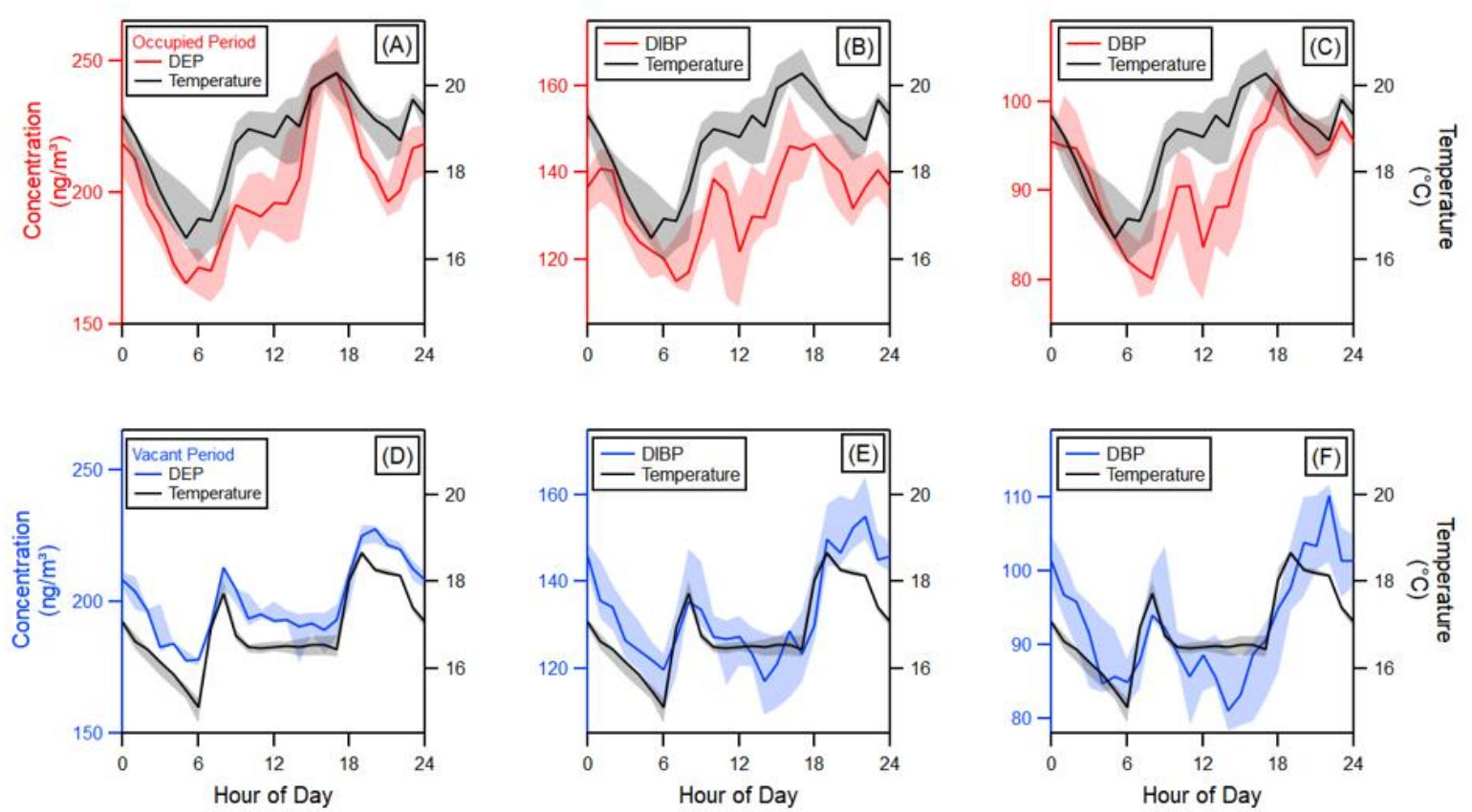

172

173 Figure S5: Diel plots (median, interquartile range by hour of day) are shown for gas-plus-

174 particle DEP, DIBP, and DBP concentrations and indoor air temperature over the occupied 175 (upper frames) and vacant (lower frames) periods.

176
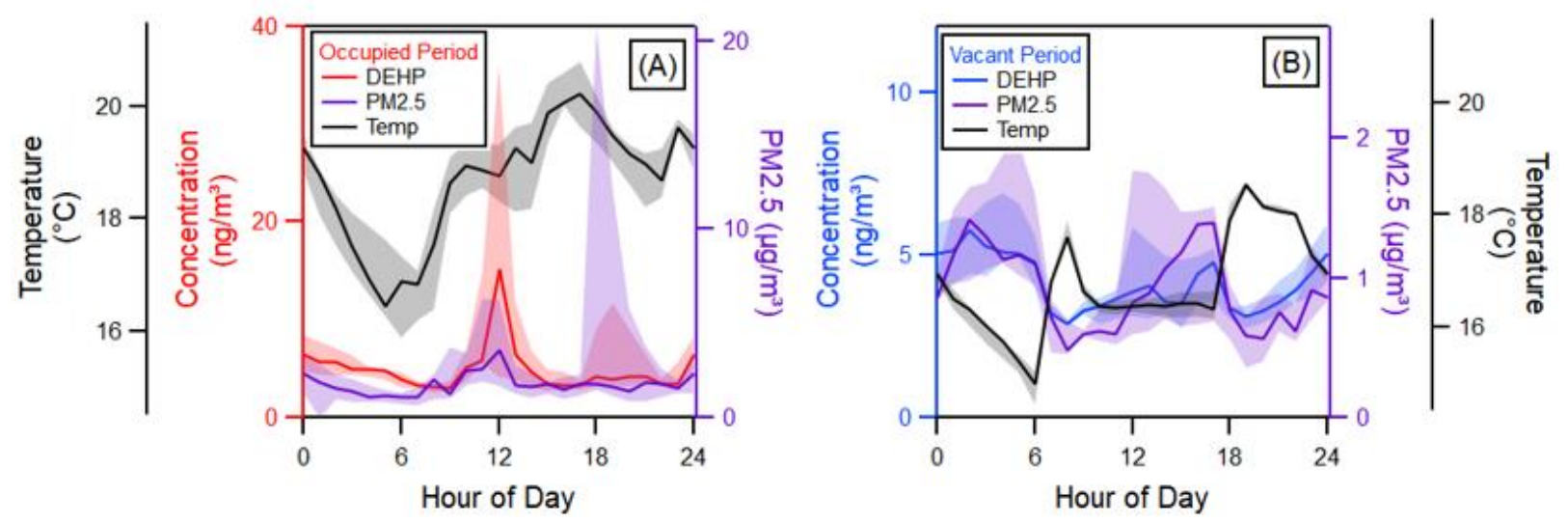

178 Figure S6: Diel plots (median, interquartile range by hour of day) are shown for gas-plus179 particle DEHP concentrations and PM2.5 particle loading over the occupied (left frame) and 180 vacant (right frame) periods. 


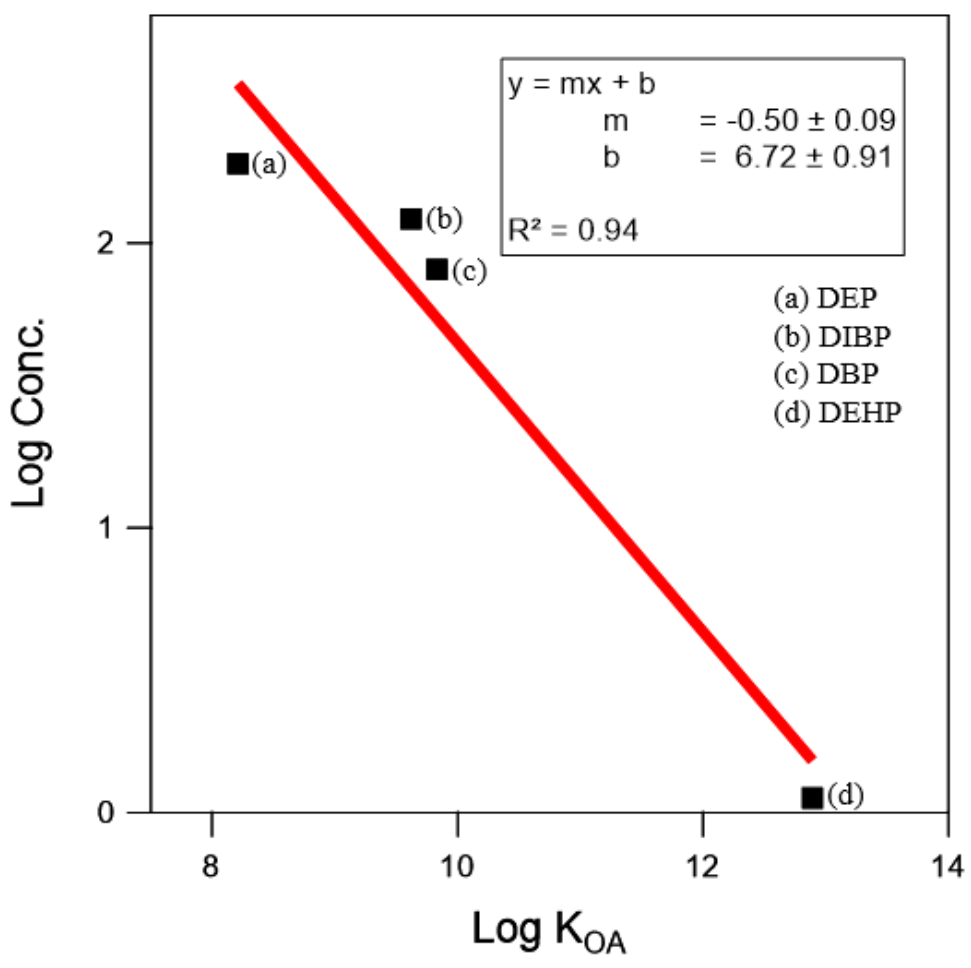

182 Figure S7: The median gas-phase concentration in $\mathrm{ng} / \mathrm{m}^{3}$ of each phthalate species over the 183 vacant period is compared against the octanol-air partition coefficient at $T=298 \mathrm{~K}$ (as reported 184 by Salthammer et al. ${ }^{10}$ ) on a log-log scale. A linear least-squares fit of the transformed data is 185 presented. 


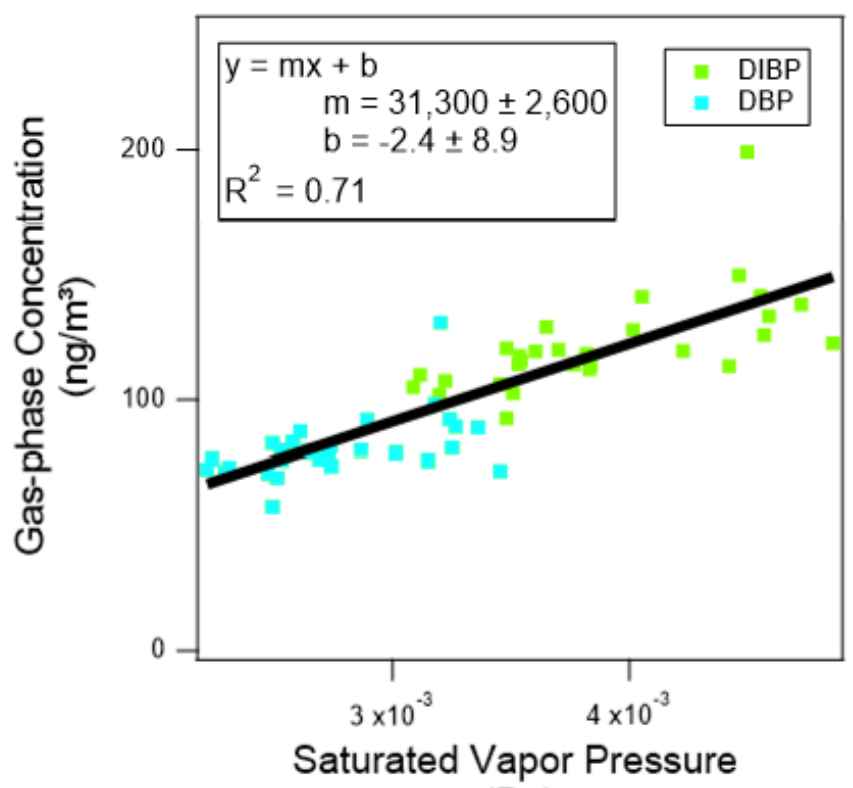

189 Figure S8: The measured gas-phase concentrations of DIBP and DBP are displayed against the 190 calculated saturation vapor pressure at the measured indoor air temperature. Vapor pressures for 191 DIBP and DBP as a function of temperature were calculated according to Wu et al. ${ }^{11}$ Units of 192 measure for the fit parameters are $\mathrm{ng} /\left\{\mathrm{m}^{3} \mathrm{~Pa}\right\}$ for the slope, $m$, and $\mathrm{ng} / \mathrm{m}^{3}$ for the intercept, $b$. 


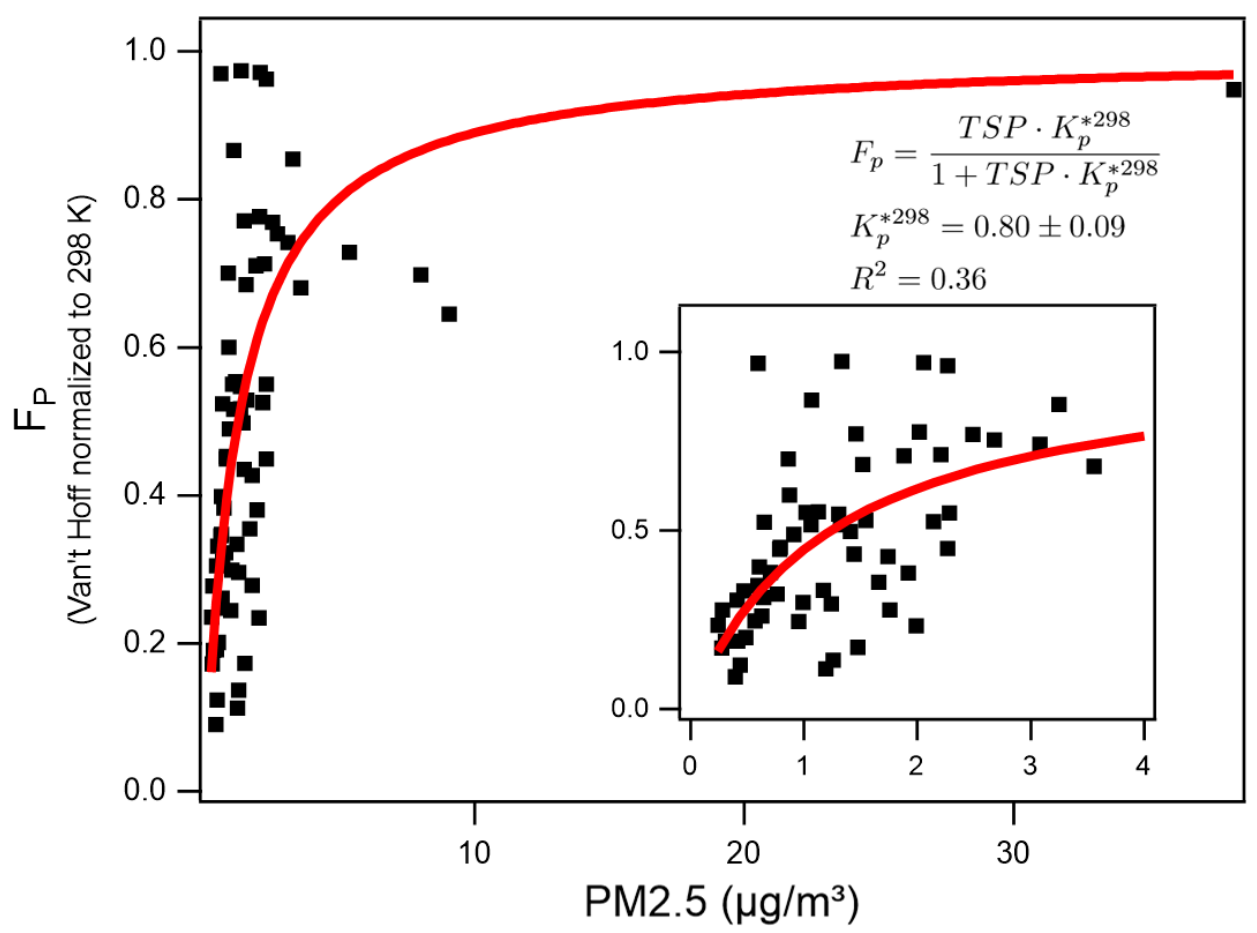

197 Figure S9: Each particle fraction value of DEHP is normalized from ambient air temperature to $198298 \mathrm{~K}$ using the van't Hoff equation and assuming $-116,700 \mathrm{~J} / \mathrm{mol}$ as the phase-change 199 enthalpy. ${ }^{12}$ Normalized particle fractions are compared against PM2.5 mass concentrations as measured throughout the campaign. The inset panel highlights the dynamic region with PM2.5

201 concentrations between 0 and $4 \mu \mathrm{g} / \mathrm{m}^{3}$. Three datapoints with experimentally determined $F_{\mathrm{p}}$ 202 greater than one were defined to have maximum particle:gas fractions of 100:1 (i.e., $F_{\mathrm{p}}=0.99$ ) to 203 facilitate the normalization process. 


\section{References}

1. Dhawan, S; Biswas, P. Sampling artifacts in denuders during phase partitioning measurements of semi-volatile organic compounds. Aerosol Sci. Technol. 2019, 53, 73-85.

2. Zhao, Y.; Kresiberg, N. M.; Worton, D. R.; Teng, A. P.; Hering, S. V.; Goldstein, A. H. Development of an in situ thermal desorption gas chromatography instrument for quantifying atmospheric semi-volatile organic compounds, Aerosol Sci. Technol. 2013, 47, 258-266.

3. Isaacman-VanWertz, G.; Yee, L. D.; Kreisberg, N. M.; Wernis, R.; Moss, J. A.; Hering, S. V.; de Sá, S. S.; Martin, S. T.; Alexander, M. L.; Palm, B. B.; Hu, W.; Campuzano-Jost, P.; Day, D. A.; Jimenez, J. L.; Riva, M.; Surratt, J. D.; Viegas, J.; Manzi, A.; Edgerton, E.; Baumann, K.; Souza, R.; Artaxo, P.; Goldstein, A. H. Ambient gas-particle partitioning of tracers for biogenic oxidation, Environ. Sci. Technol. 2016, 50, 9952-9962.

4. Isaacman-VanWertz, G.; Sueper, D. T.; Aikin, K. C.; Lerner, B. M.; Gilman, J. B.; de Gouw, J. A.; Worsnop, D. R.; Goldstein A. H. Automated single-ion peak fitting as an efficient approach for analyzing complex chromatographic data. J. Chromatogr. A 2017, 1529, 81-92.

5. Isaacman, G.; Kreisberg, N. M.; Yee, L. D.; Worton, D. R.; Chan, A. W. H.; Moss, J. A.; Hering, S. V.; Goldstein, A. H. Online derivatization for hourly measurements of gas- and particle-phase semi-volatile oxygenated organic compounds by thermal desorption aerosol gas chromatography (SV-TAG). Atmos. Meas. Tech. 2014, 7, 4417-4429.

6. Yee, L. D.; Isaacman-VanWertz, G.; Wernis, R. A.; Meng, M.; Rivera, V.; Kreisberg, N. M.; Hering, S. V.; Bering, M. S.; Glasius, M.; Upshur, M. A.; Gray Bé, A.; Thomson, R. J.; Geiger, F. M.; Offenberg, J. H.; Lewandowski, M.; Kourtchev, I.; Kalberer, M.; de Sá, S.; Martin, S. T.; Alexander, M. L.; Palm, B. B.; Hu, W.; Campuzano-Jost, P.; Day, D. A.; Jimenez, J. L.; Liu, Y.; McKinney, K. A.; Artaxo, P.; Viegas, J.; Manzi, A.; Oliveira, M. B.; de Souza, R.; Machado, L. A. T.; Longo, K.; and Goldstein, A. H. Observations of 
sesquiterpenes and their oxidation products in central Amazonia during the wet and dry seasons. Atmos. Chem. Phys. 2018, 18, 10433-10457.

7. Stein, S. E.; Mirokhin, Y.; Tchekhovskoi, D.; Mallard, W. National Institute of Standards and Technology (NIST) Mass Spectral Search Program for the NIST/EPA/NIH Mass Spectral Library, National Institute of Standards and Technology Standard Reference Data Program, Gaithersburg, 2014.

8. Hu, M.; Peng, J.; Sun, K.; Yue, D.; Guo, S.; Wiedensohler, A.; Wu, Z. Estimation of sizeresolved ambient particle density based on the measurement of aerosol number, mass, and chemical size distributions in the winter in Beijing. Environ. Sci. Technol. 2012, 46, 99419947.

9. Zhou, J.; Chen, A.; Cao, Q.; Yang, B.; Chang, V.W.C.; Nazaroff, W.W. Particle exposure during the 2013 haze in Singapore: Importance of the built environment, Build. Environ. 2015, 93, 14-23.

10. Salthammer, T.; Zhang, Y.; Mo, J.; Koch, H. M.; Weschler, C. J. Assessing human exposure to organic pollutants in the indoor environment. Angew. Chem., Int. Ed. 2018, 57, 1222812263.

11. Wu, Y.; Eichler, C. M. A.; Chen, S.; Little, J. C. Simple method to measure the vapor pressure of phthalates and their alternatives. Environ. Sci. Technol. 2016, 50, 10082-10088.

12. Salthammer, T.; Goss, K.-U. Predicting the gas/particle distribution of SVOCs in the indoor environment using poly parameter linear free energy relationships. Environ. Sci. Technol. 2019, 53, 2491-2499. 